In the second group (summer hay-fever only) there are five instances of complete freedom, one of which was obtained the previous year and last year remained free without treatment. In the two remaining cases, which were practically free, the treatment could not be regarded as ideal, as one patient was late and treatment was continued during the season, while the second was to a great extent out of town.

In the third group (combined summer and autumnal variety) there are, as regards the summer type, six instances of complete freedom out of six cases treated last year; the case with complete freedom during the previous year remaining free last year without treatment. As regards the autumnal type, there are two instances of complete freedom, three of practical free-

TABLE 2.-DEGREE OF PROTECTION

\begin{tabular}{|c|c|c|c|c|c|c|}
\hline & $\begin{array}{c}\text { Group 1 } \\
\text { (Spring } \\
\text { In- } \\
\text { cluded) }\end{array}$ & $\begin{array}{c}\text { Group } 2 \\
\text { (Sum- } \\
\text { mer } \\
\text { Only) }\end{array}$ & $\begin{array}{l}\text { Group 3 } \\
\text { (Summer } \\
\text { and } \\
\text { Autumin) }\end{array}$ & $\begin{array}{c}\text { Group } 4 \\
\text { (Aut- } \\
\text { umn } \\
\text { Only) }\end{array}$ & Number & Per Cent. \\
\hline $\begin{array}{l}\text { Complete freedom } \\
\text { Praetical freedom } \\
\text { Marked beneflt... }\end{array}$ & $\begin{array}{l}2 \\
1 \\
0\end{array}$ & $\begin{array}{l}5 \\
2 \\
0\end{array}$ & $\begin{array}{l}3 \\
\mathbf{3} \\
\mathbf{2}\end{array}$ & $\begin{array}{r}10 \\
8 \\
3\end{array}$ & $\begin{array}{r}20 \\
14 \\
5\end{array}$ & $\left.\begin{array}{l}46.5 \\
32.6 \\
11.6\end{array}\right\} 90.7$ \\
\hline Little or no benefit & $\mathbf{0}$ & 0 & 0 & $\mathbf{3}$ & 3 & 7.01 \\
\hline Aggravated....... & $\mathbf{0}$ & 0 & 0 & 1 & 1 & $2.3]^{3}$ \\
\hline Total........... & 3 & 7 & 8 & 25 & 43 & \\
\hline
\end{tabular}

dom and one of marked benefit. In these less satisfactory results, the factors militating against success, such as lateness, interruption and incompleteness, are noticeable. Four cases were treated by the combined method; and despite difficulties in treatment, and the factors as noted in the-last column, two complete and two practical "reliefs" were obtained.

In the fourth group (twenty-five cases of the autumnal type) twenty-two cases were treated last year, among which there are nine instances of complete and six of practical freedom; three patients obtained marked benefit, three slight or no benefit, and in one case the symptoms were aggravated. Success was jeopardized by the poor opportunity for treatment in one of the three obtaining only marked benefit, and as well, in two of the three with no benefit. No such explanation, however, can be advanced as a cause for one case of no benefit, and for the case which was aggravated, but which the previous year was completely protected.

Table 2 summarizes the degree of protection. In this the results for each season are not taken into account as they were in Table 1 , the most unfavorable outcome being taken as indicative of the protection obtained.

Local application was employed with twenty cases out of the thirty-three in Groups 3 and 4. These numbers are obviously too small to serve as a basis for any conclusion; moreover, the different circumstances militating against a fair trial were too frequently present in both the injection and combined treatment groups. Without attempting to assess these varying factors, the percentage results obtained show that the combined treatment in contrast to injections alone was slightly - more successful. The figures for combined treatment versus injection alone respectively are in complete freedom 45 and 30.7 per cent., in practical freedom 35 and 30.7 per cent., in marked benefit 10 and 23 per cent., and in no benefit, including aggravation, 10 and 15.3 per cent.

In Table 1 , the results of sensitization after treatment have been noted because a consideration of these suggest that, when this is marked, the combined treatment may be contraindicated. An attempt was made to ascertain the correlation between the cutaneaus and the nasal, reactivity in a few cases. The contrast. afforded among these cases, so tested showed a fairly marked degree of : similarity, when one considers the relative character of the amounts used and the difference in the methods used to elicit this. Apart from any theoretical considerations, an analysis of the degree of post-treatment sensitization and the therapeutic results show that, in both Groups. 3 and 4, there were six cases treated by the combined method in which the post-treatment sensitization was marked. The results in these were three of no benefit, including the one case of aggravation, two of marked relief, and one of practical freedom. This proportion of poor success or failure is greater than in the other treated by the combined method, and also greater than that obtained in similar cases treated by injection alone. Admittedly, the numbers are too small, but the effect at least raises the question of the advisability of using local application in those cases in which previous tests have shown marked cutaneous sensitization after injections alone, especially if the results obtained had been satisfactory.

The conclusions drawn by MacKenzie, using a different method of local application by itself, combined with and contrasted to hypodermic injections alone, left me with the impression that he considered its further use justified. My results lead me to concur with the restriction that it may be contraindicated in certain individuals.

\section{OBSERVATIONS ON THE DISTRIBUTION OF VITAMIN B*}

The absolute necessity of an adequate supply of vitamin $B$, in the dietary of growing animals, if growth is to be maintained at a normal rate, is a fact that has been established beyond question. Among the earlier observations on this point were those of Osborne and Mendel, ${ }^{1}$ Hopkins ${ }^{2}$ and Stepp. ${ }^{3}$ These authors, working independently, arrived at the same conclusions, although their ideas as to the nature of the hypothetic substance were at variance. Since that time, research has led to the demonstration of vitamin B in "milk, rice, wheat embryo, cotton seed, pancreas, maize kernel, wheat, oat, kidney beans, yeast, ivy beans, peanut meal" 4 and many plants used as food in the form of "greens," such as asparagus, celery, dandelions and lettuce.

An adequate supply of vitamin $B$ is necessary not only because of the growth stimulating properties of the vitamin itself but also because of its influence on the general food intake of the animal. ${ }^{6}$ All experimenters in the field of accessory food substances have observed the stimulating effect of an adequate vitamin supply on

* From the Department of Bacteriology, School of Hygiene and Public Health, Johns Hopkins University.
1. Osborne, T. B., and Mendel, L. B.: Pub. 156, Parts 1 and 2,

Carnegie Institution of Washington, 1911

2. Hopkins, F. G.: J. Physiol. 44: 425, 1912.

3. Stepp, W.: Biochem. Ztschr. 22: 452, 1909; Ztschr. f. Biol. 5r : $135,1911-1912$.

4. Osborne, T. B., and Mendel, L. B.: J. Biol. Chem. 52: 309 (Dec.) 1917 .

5. Osborne, T. B., and Mendel, L. B.: Further Observations on tile Distribution of Vitamin B in Some Vegetable Foods, J. A. M. A. 78:

1121 (April 15) 1922.

6. Cowgill, G. R.: Am. J. Physiol. 57: 420 (Oct.) 1921. 
the appetite of their: animals: These substances need be present in only iminute quantity, but their presence is essential. It is this rekation to appetite and food intake that prompts this report:-

In the counse of certain studies on bacterial nutrition it became of interest; at: one time, to test the basal ingredients of culture medium of organic origin, i. e., peptone and beef extract, for their vitamin content. This research was especially indicated, since the literature is 'not clear on this poirt: Bayliss, ${ }^{7}$ in his discussion of the growth promoting principle "Bios," says: "It is present in Liebig's meat extract and commercial peptone." Funk ${ }^{8}$ reports the presence of vitamin in meat juice and meat extract, and Osborne and Mendel ${ }^{4}$ as well found " small amount of the water soluble food hormone" in meat extract.

\section{EXPERIMENTAL METHODS USED}

The tests' were carried out on young rats, weighing from 50 to 75 gm., which were failing to grow on a diet known to be adequate to promote growth at a normal rate when sufficient vitamin $B$ was supplied. The food nixture consisted of casein, 18 per cent.; sugar, 17 ; starch 52.5 ; butter fat, 10 , and salt mixture, 2.5 . Inspection shows this mixture to be adequate except for the deficiency of vitamin $B$.

The peptone and beef extract were added to this ration in place of definite quantities of starch. Each substance was tested in the amount of 2.5 and 7.5 per cent. of the ration.

\section{RESULTS}

In no case was the decline of the experimental animals stopped by the addition to the ration of definite quantities of either peptone or beef extract.

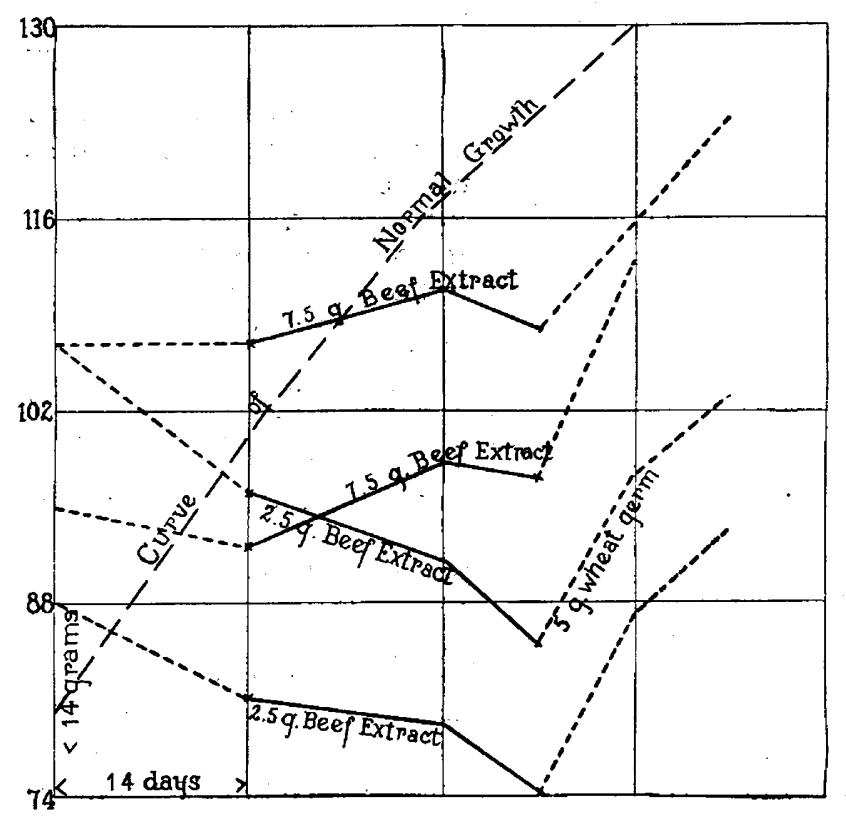

Chart 1.-Failure of rats that had declined on a diet deficient in vita. min $B$ to recover when beef extract was added as a source of this factor.

The accompanying charts show typical growth curves of rats fed this experimental ration. The initial period of decline, on a diet deficient in vitamin $\mathrm{B}$, is indicated by the dotted line. Following this is the period when the animals were fed the same basal ration plus the

7. Bayliss, W. M.: Principles of General Physiology, 1915, p. 260. 8. Funk, C.: München. med. Wchnschr., 1913, p. 2614. peptone or beef extract and failed to recover; and finally there is the period of recovery, indicated by the rapid. rise of the growth curve when the basal ration was supplemented by wheat germ as a known source of vitamin $B$.

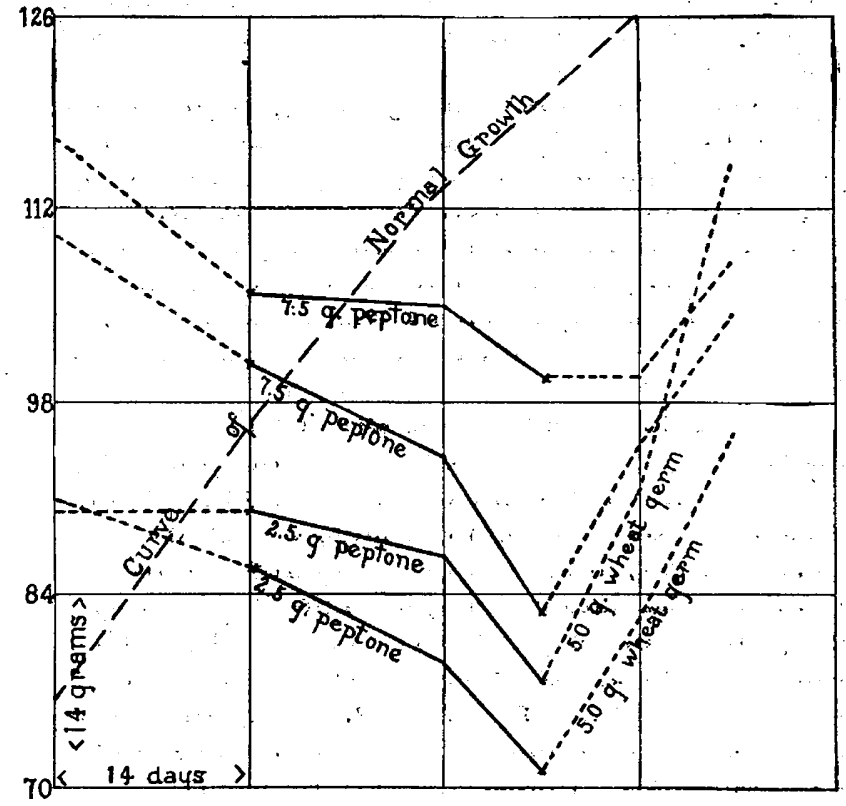

Chart 2,-Failure of 'rats that had' declined on 'a diet deficient in vitamin $B$ to. recover when peptone was added as a source of this factor.

\section{CONCLUSIONS}

Commercial beef extract and peptone are devoid of the water soluble vitamin $B$.

Nore-The importance of these observations in connection with the use of beef extract in convalescence will be recognized by all who heard Dr. Mendel at the recent Congress of American Physicians and Surgeons in Washington describe the relation of vitamin $B$ to appetite and food intake.

\section{THE PRACTICAL APPLICATION OF THE RESULTS OF VITAMIN STUDIES}

\section{EMMETT HOLT, M.D. NEW YORK}

Our knowledge of vitamins has given a new basis for the evaluation of foods. Certain articles which, from the point of view of their energy value, are almost worthless have been shown to possess great nutritive value. Their importance is not suggested by their chemical analysis. They furnish something very essential in a human diet.

The tomato, cabbage, spinach, lettuce, chard and all the green or leafy vegetables are composed chiefly of cellulose, water and inorganic salts. Fruits have sugar, vegetable acids, water and salts, but none of these things suggest their essential value as foodstuffs.

Many of our foods we no longer eat in their natural state. The conditions of modern life have made necessary the transportation of foods for long distances and the preservation and storage of food in immense quantities for long periods. A certain amount of injury is done to.our vegetables, fruits; milk, meats and grain by the processes to which they are subjected in preparation, preservation and storage. The study of vitamins has helped us to understand, to some degree at least, 